\title{
DIAGNOSTIC ACCURACY OF ENDOSCOPIC BIOPSY VERSUS MUCOSAL RESECTION IN DETECTING HISTOPATHOLOGIC CHANGES OF BARRETT'S ESOPHAGUS AND ITS RELATED SUPERFICIAL LESIONS.
}

\author{
Hany M. Elsadek, Mamdouh M. Radwan* \\ Department of Internal Medicine, Faculty of Medicine, Zagazig University \\ Pathology Department, Royal Commission Medical Center (RCMC), Yanbu, Saudi Arabia*
}

\begin{abstract}
Background: In most patients with Barrett's esophagus (BE), endoscopic surveillance for early detection of dysplastic or neoplastic changes depends on the results of forceps biopsy. Endoscopic mucosal resection (EMR) is rapidly growing as an excellent diagnostic and therapeutic method for BE with dysplastic and early neoplastic changes. It is not entirely clear what is the agreement between the histopathologic diagnosis based on biopsy specimen versus that based on mucosal resection specimen. Objective: The aim of this study was to check the accuracy of biopsy for precise histopathologic diagnosis of dysplasia and neoplasia, compared to EMR in patients with BE and its related superficial esophageal lesions. Methods: During the period from December 2011 to December 2013, 24 patients with previously diagnosed BE (18 men, 6 women, mean age $49.75 \pm 13.3$ years, range $32-83$ years) underwent routine regular surveillance endoscopic examination. Targeted biopsies were taken from the visible lesions in 12 patients with macroscopically suspicious lesions of the esophagus (group 1), and 4 quadrant biopsies were taken from BE segments in 12 patients without visible lesions (group 2). Then EMR was performed within 3 weeks, in all patients. Results: Initial histopathologic diagnosis of biopsies were: non dysplastic BE (NDBE) in 11 cases, low-grade dysplasia (LGD) in 7 cases, high-grade dysplasia (HGD) in 4 cases, intramucosal carcinoma (IMC) in one case, and invasive adenocarcinoma (IAC) in one case. EMR based diagnosis was identical with biopsy based diagnosis in only 14 cases $(58.33 \%)$. The diagnosis differed in 10 cases $(41.67 \%) ; 9$ of them (37.5\%) had "Upgrading" (i.e. diagnosis towards a higher degree of dysplasia) of biopsy based diagnosis in comparison to EMR based diagnosis, while, only one case (4.17\%) had "Downgrading" (i.e. diagnosis towards a lower degree of dysplasia) of biopsy based diagnosis in comparison to EMR based diagnosis. Conclusions: Endoscopic biopsy is not a satisfactory method for accurate diagnosis of esophageal dysplastic or neoplastic changes in BE patients with or without suspicious superficial lesions. EMR should therefore be the preferred diagnostic method in such patients.
\end{abstract}

Keywords: Barrett's esophagus - dysplasia- adenocarcinoma - biopsy - mucosal resection

\section{INTRODUCTION}

B arrett's esophagus (BE) is a sequel of gastroesophageal reflux disease (GERD). Prevalence of BE in western countries is about $2 \%$ in general population and around $5-15 \%$ in chronic GERD patients. ${ }^{(1,2)} \mathrm{BE}$ is a premalignant lesion, that may progresses through stages of dysplasia to cancer, with esophageal adenocarcinoma (EAC) occurring at an overall incidence rate of $0.4-0.5 \%$ per year. ${ }^{(3)}$ The incidence of EAC in BE cases with high grade dysplasia (HGD) is above 6\%. ${ }^{(4)}$ There are worldwide different endoscopic surveillance protocols for patients with $\mathrm{BE}$ and different grades of dysplasia, however the commonest surveillance frequency used is every 3-5 years for BE without dysplasia, every 6-12 months for BE with LGD (low grade dysplasia) and every 3 months for BE with HGD without intervention. ${ }^{(5-8)}$ There is a lack of agreement concerning the optimal management of dysplasia and early EAC, therefore, management practices vary considerably among different medical centers. There remains heterogeneity in the management of HGD/early EAC throughout the world; the primary alternatives include managing
HGD with surveillance alone, endoscopic therapy to remove HGD or early EAC, or surgical resection (esophagectomy). ${ }^{(6-8)}$

The main role of EMR in BE patients is the curative treatment of prominent lesions and neoplasms without lymph node involvement or distant metastases. Thus, its use in correct indication requires a correct disease staging which can include endoscopic, histological and sometimes radiographic criteria. ${ }^{(9)}$ Endoscopic mucosal resection is used for the en-bloc excision of lesions smaller than $2 \mathrm{~cm}$ or for the resection of greater lesions in various fragments, which is called a "piecemeal" resection. ${ }^{(9)}$ From a technical point of view, EMR includes several systematic steps of which submucosal injection is very useful; it allows the creation of a "security chamber" that minimizes the complication risks. Subsequent resection using a diathermy snare, cap-assisted as well as band ligator techniques can then be performed..$^{(10-13)}$

Upon endoscopic surveillance, 4 quadratic biopsies are to be taken from BE segment. Moreover, visible prominent lesions found related to $\mathrm{BE}$ segment are indicated for biopsy sampling or even endoscopic 
resection independently on the result of histological examination of biopsies. Further endoscopic interventions or surgical interference may be indicated based on the result of biopsy examination, such as radiofrequency ablation (RFA) for HGD or IMC (intra mucosal carcinoma) and esophagectomy for invasive $\mathrm{EAC}{ }^{(7)}$

Recent publications have reported the development of EAC in patients who were treated by RFA for HGD in BE field. ${ }^{(14-15)}$ These reports should raise the speculation that these patients possibly had cancer from the start, but not detected by standard biopsy. On the basis of this report, the decision to carry out this prospective study was made.

The aim of this prospective study was to clear whether the agreement in histopathologic diagnosis between forceps biopsies and EMR is sufficient when examining $\mathrm{BE}$ and its related superficial lesions.

\section{METHODS:}

This prospective study was done at gastroenterology and pathology departments, Royal Commission Medical Center (RCMC), Yanbu, Saudi Arabia, during the period from December 2011 to
December 2013. The study was performed on 24 patients undergoing programmed upper gastrointestinal endoscopy for surveillance of previously diagnosed BE, with or without dysplasia. Patients were categorized into two groups. Group A comprised 12 patients in whom grossly apparent superficial lesions suspicious of neoplasia were found in relation to the $\mathrm{BE}$ segment, these were type 0 lesions according to Paris classification of suspected neoplastic lesions in the digestive tract (table 1). ${ }^{(16)}$ Group B comprised 12 patients with no grossly apparent suspicious lesions found in relation to the BE segment. Patients excluded from the current study were those who had a previous endoscopic interventional therapy, those who had a previously diagnosed advanced EAC (lymph node or distant metastases) or those in whom the encountered esophageal lesion was anatomically not related to the $\mathrm{BE}$ segment or morphologically exceeding the type 0 (superficial) lesion described in Paris classification. Moreover, patients having uncorrected coagulopathy or any contraindication to standard endoscopy such as severe cardiopulmonary comorbidities were excluded.

Table 1 The macroscopic classification of digestive-tract cancer

\begin{tabular}{ll}
\hline Superficial type $\mathbf{0}$ & Superficial protruding or nonprotruding lesions \\
\hline Advanced type $\mathbf{1}$ & Protruding carcinoma, attached on a wide base \\
\hline Advanced type $\mathbf{2}$ & Ulcerated carcinoma with sharp and raised margins \\
\hline Advanced type $\mathbf{3}$ & Ulcerated carcinoma without definite limits \\
\hline Advanced type $\mathbf{4}$ & Nonulcerated, diffusely infiltrating carcinoma \\
\hline Advanced type $\mathbf{5}$ & Unclassifiable advanced carcinoma \\
\hline
\end{tabular}

All patients received information concerning the technique used and its possible complications. Informed consent for performing endoscopy and EMR was obtained from every patient. All endoscopies were performed by an experienced endoscopist, as outpatient procedures and under deep sedation controlled by an anesthesiologist. Upper gastrointestinal endoscopy was done using high definition endoscopy and narrow band imaging (NBI) (GIF H180, Olympus ${ }^{\circledR}$ ). After the introduction of endoscope, esophageal mucosa was rinsed with water, and $\mathrm{BE}$ segment and its related superficial lesions were delineated. For lesions with poorly defined margins chromoendoscopy with indigo carmine stain was used.

A detailed view (using magnification and NBI) of the BE segment was recorded and 4 quadratic biopsies were taken. The endoscopic appearance of type 0 lesions were assessed and described according to Paris classification (table 2), and targeted biopsies were taken from them. 
Table 2: The macroscopic classification of type 0 digestive-tract lesions, with a superficial appearance at endoscopy

\section{Protruding}

\begin{tabular}{cl}
\hline Pedunculated & 0-Ip \\
\hline Sessile & 0-Is \\
\hline Nonprotruding and nonexcavated &
\end{tabular}

Nonprotruding and nonexcavated

\begin{tabular}{ll}
\hline Slightly elevated & 0-IIa \\
\hline Completely flat & 0 -IIb \\
\hline Slightly depressed & 0 -IIc \\
\hline Elevated and depressed types & 0-IIc + IIa or 0 -IIa + IIc
\end{tabular}

\section{Excavated}

Ulcer

0-III

Excavated and depressed types

Endoscopic resection was performed in another endoscopic session (as it was technically difficult to do in the same session with biopsy), but not more than 3 weeks later to avoid false positive results of EMR examination that may result from fibrosis at the biopsy site. ${ }^{(17)}$ Lesions were marked circumferentially using argon plasma with a $40 \mathrm{~W}$ power. Submucosal injection was then performed with isotonic saline. Techniques used for mucosal resection after submucosal injection were loop resection (using a diathermy snare) and cap-assisted resection as well as band ligator-assisted resection. $^{(12,18)}$ After resection of the lesion, the sample was extracted using a retrieval net or basket. Surgical back-up was available for the event of uncontrolled hemorrhage or perforation.

\section{Histopathologic processing:}

In accordance with a previously published protocol $^{(19)}$; all EMR specimens were marked with India ink along their lateral and deep margins, then were stretched and pinned to wax blocks, fixed in $10 \%$ formaldehyde for 24 hours, and then serially sectioned at 2-mm intervals before routine histologic processing of all tissue. Sections were stained with $\mathrm{H} \& \mathrm{E}$ for microscopic analysis.

Classification of the lesions on histopathologic examination was based on previously published criteria $^{(20)}$, in accordance with the Vienna classification of gastrointestinal epithelial neoplasia. ${ }^{(21)}$ In NDBE, there were metaplastic columnar epithelium containing goblet cells with
-IIc + III or 0-III + IIc

uniform glandular architecture, basally located nuclei with smooth membranes, and preserved polarity, normal nuclear/cytoplasmic (N/C) ratio. LGD was characterized by glandular proliferation without complex branching or villous architecture. The glands were lined by crowded, elongated cells with hyperchromatic and basilar pseudostratified nuclei. HGD displayed more pronounced architectural abnormalities, with gland branching and budding. Vesicular nuclei with prominent nucleoli, partial or total loss of nuclear polarity, and a high N/C ratio were also commonly observed. Mitoses were usually numerous. IMC required loss of the maturation of the epithelium, small clusters of epithelial cells between the glands, invading the original and the newly formed muscularis mucosae, abortive microglands and irregular large nuclei with the presence of mitosis and loss of cytoplasm. IAC was diagnosed when malignant cells, singly or in groups, infiltrate beyond the basement membrane. Staging of the lesions was completed by CT scan and/or endoscopic ultrasonography if necessary.

\section{Statistical evaluation:}

Basic methods of descriptive statistics were used e.g. mean and standard deviation. Inter-rater agreement between biopsy based diagnoses and EMR based diagnoses was determined by using the kappa statistic, a widely used and accepted mathematical coefficient that provides a measure of agreement between two observers (or methods), accounting for agreement other than that occurs by chance only. 
The strength of rater agreement was categorized as follows: $0.00-0.20$, slight; $0.21-0.40$, fair; $0.41-$ 0.60 , moderate; 0.61-0.80, substantial; 0.81-1.00, almost perfect. Corresponding $95 \%$ confidence interval (CI) for the kappa value was calculated. ${ }^{(22)}$

\section{RESULTS}

Overall, we studied $24 \mathrm{BE}$ patients (18 men, 6 women, mean age $49.75 \pm 13.3$ years, range $32-83$ years). In group A patients, superficial lesions

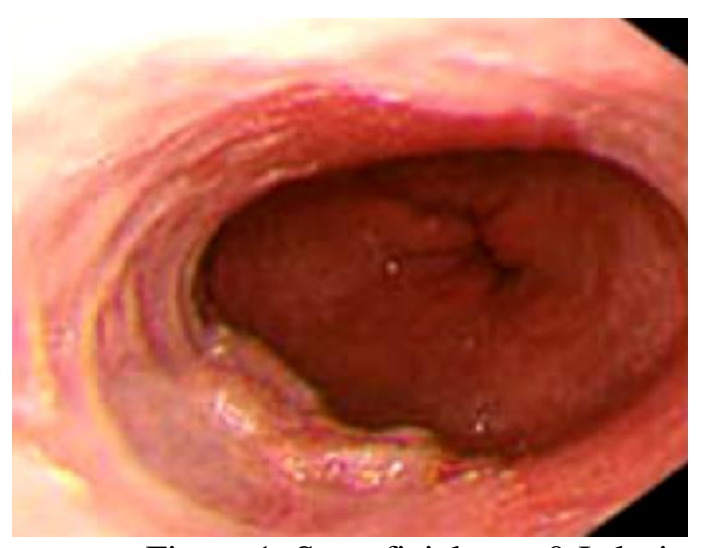

Figure 1: Superficial type 0-Is lesion

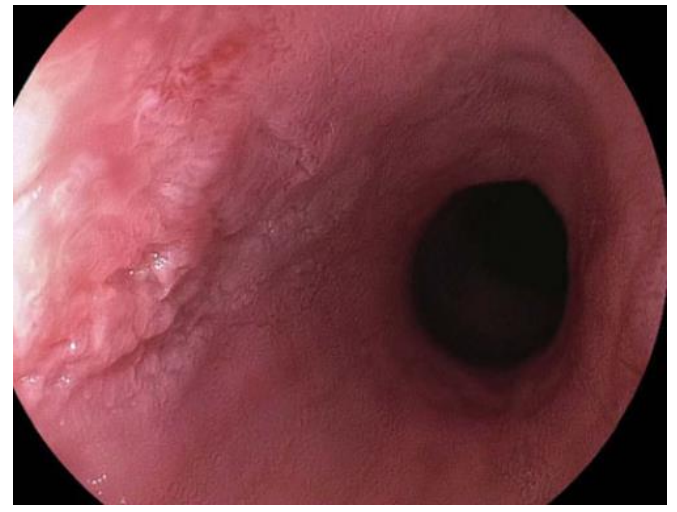

Figure 3: Superficial type 0-IIb lesion
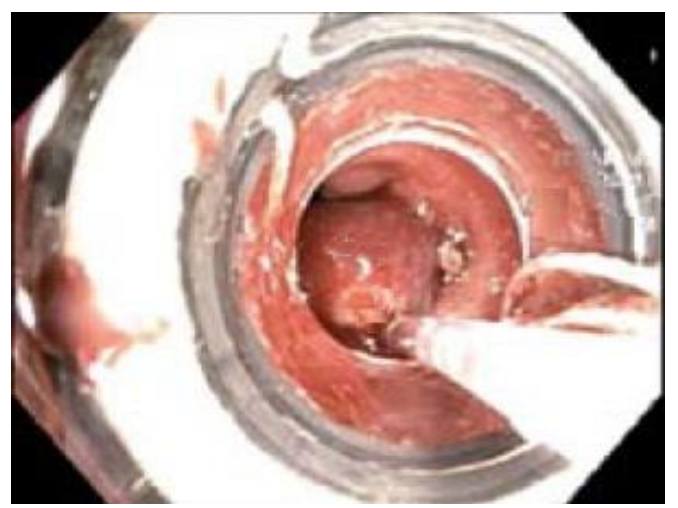

Figure 5: EMR using band ligation. related to the BE segment were found, that were, according to Paris Classification, type 0-Is ( 2 cases), type 0 -IIa (6 cases), type 0 -IIb (3 cases) and type 0IIc (1 case) (figures 1-4). Forceps biopsies and EMR (figure 5) specimens were taken from these lesions. In group B patients, no obvious lesions related to $\mathrm{BE}$ segment were found, so, forceps biopsy and EMR specimens were taken from BE segment.

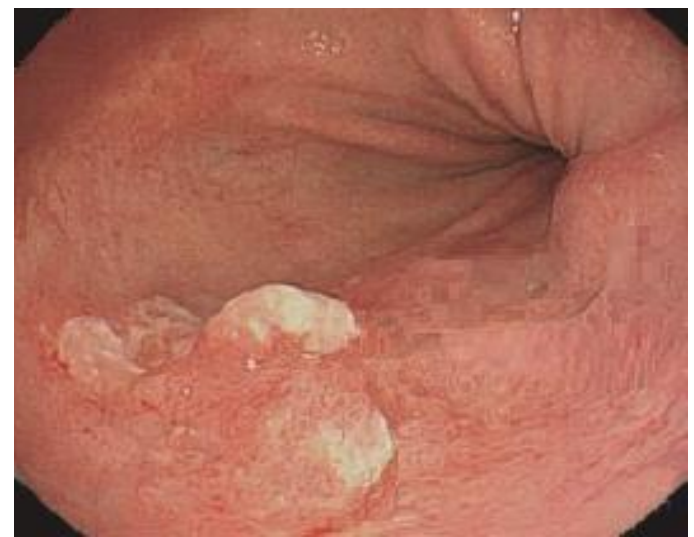

Figure 2: Superficial type 0-IIa lesion

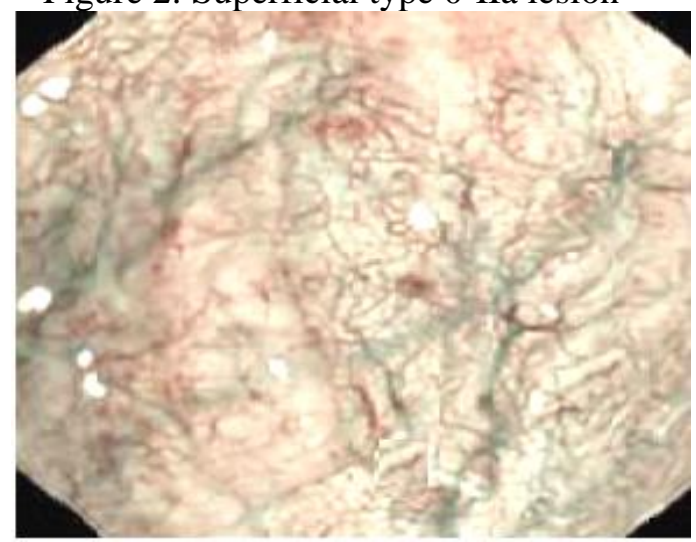

Figure 4: Superficial type 0-IIb lesion (NBI)

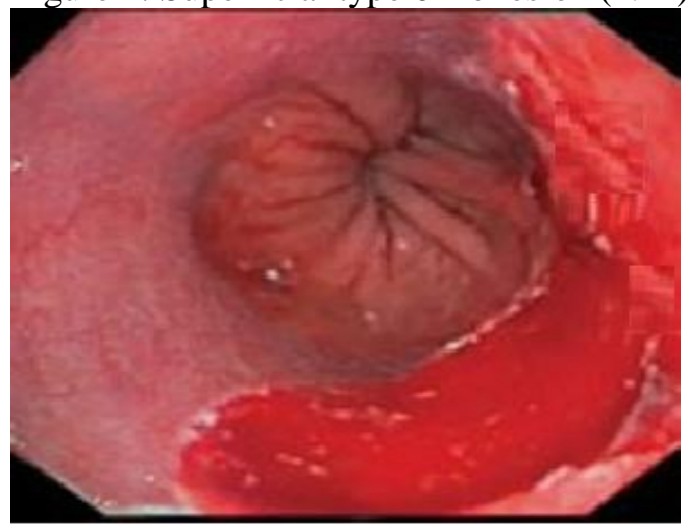

Figure 6: Row area after EMR 
The differences in histopathologic diagnoses among all patients according to the type of the specimen (biopsy versus EMR) were shown in figure (7). According to kappa statistic of inter-rater agreement, figure (8) and table (3) described the agreement and disagreement between biopsy based and EMR based histopathologic diagnoses; an agreement between biopsies and EMR was found only in 14 cases $(58.33 \%)$, while disagreement between them was found in 10 cases $(41.67 \%), \mathrm{Kappa}=0.430,95 \% \mathrm{CI}$ : $0.170-0.690$, the strength of agreement is considered to be 'moderate'. An "upgrading" diagnosis was made by EMR (i.e., a higher degree of dysplasia or neoplasia than that diagnosed with biopsy) in 9 cases (37.5\%), and a "downgrading" diagnosis was made by EMR (i.e., a lower degree of dysplasia or neoplasia than that diagnosed with biopsy) in one case $(4.17 \%)$.

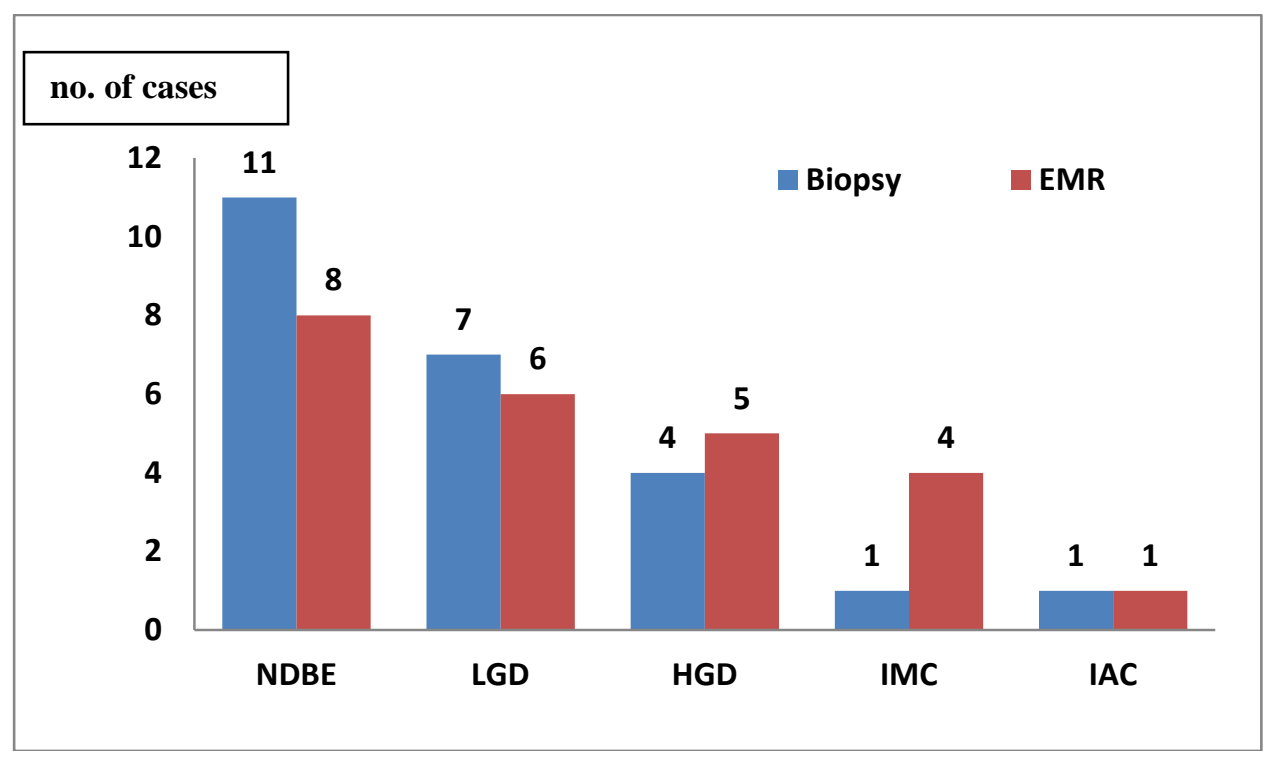

Figure 7: Differences in histopathologic diagnoses according to the type of the specimen (biopsy versus EMR).

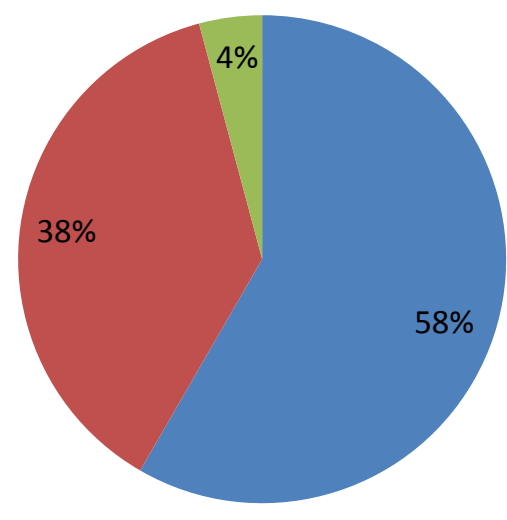

Agreement $(n=14)$

Upgrading ( $n=9)$

Downgrading ( $n=1)$

Figure 8: Agreement and disagreement between biopsy based and EMR based diagnoses. 
Table 3: Agreement and disagreement in histopathologic diagnosis between biopsies and EMR; the agreement is marked with blue shading and bold numbers, while the upgrading diagnosis is marked by pink shading and the downgrading diagnosis is marked by green shading.

EMR based histologic diagnosis

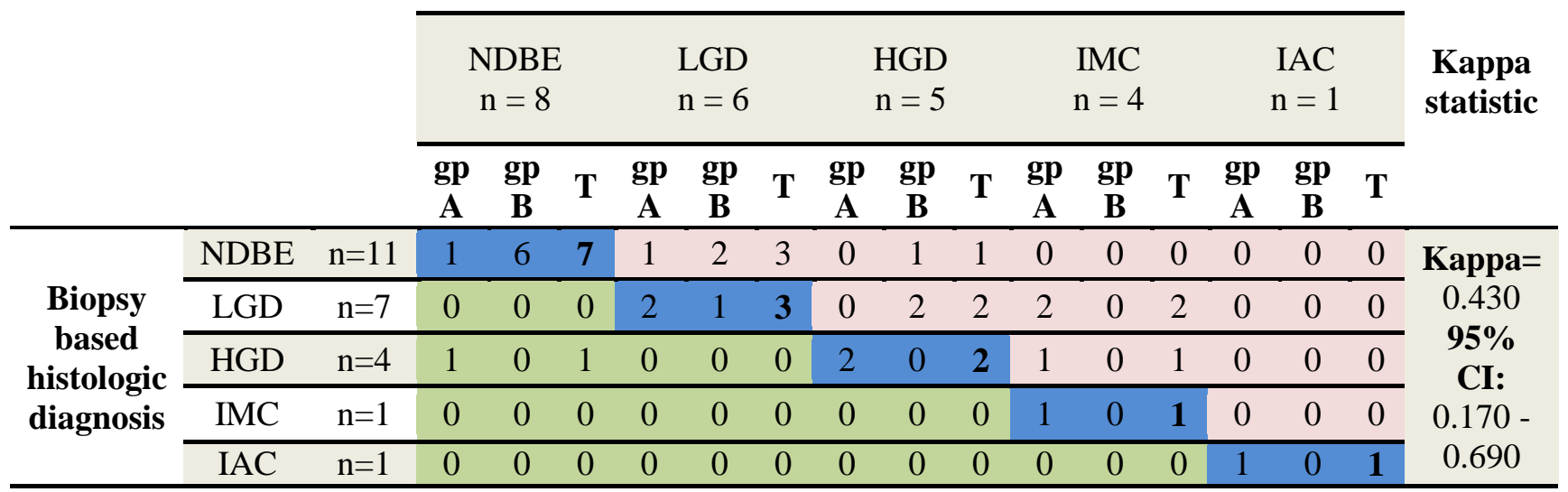

gp $\mathrm{A}=$ group $\mathrm{A}$, gp $\mathrm{B}=$ group $\mathrm{B}, \mathrm{T}=$ total

The biggest disagreement between biopsy based and EMR based diagnoses was found in 7 patients with biopsy finding of LGD; 4 of them $(57.14 \%)$ showed different EMR based diagnoses, with upgrading to HGD in two cases, and to IMC in the other two cases. The second big disagreement was found in the 4 patients with biopsy finding of HGD; of them two patients (50\%) showed different EMR based diagnoses, with upgrading to IMC in one case, and downgrading to $\mathrm{NDBE}$ in the other one (table 3).

There was only one case of IAC in this study, that was diagnosed in agreement by both biopsy and EMR (table 3), this patient was referred for surgery. Moreover, the 9 patients with established HGD (5 cases) or IMC ( 4 cases) according to EMR based histopathologic diagnosis (table 3), were referred for endoscopic intervention (RFA), 5 out of these 9 cases had previous biopsy based lower grading diagnoses (NDBE/LGD) that did not mandate any intervention.

There was no significant difference between group A patients and group B patients regarding agreement between biopsy based and EMR based diagnoses $(\mathrm{P}=1)$, as there were 7 cases of agreement and 5 cases of disagreement in each group (table 4).

Mild to moderate bleeding was seen at most EMR sites (figure 6) that stopped immediately spontaneously. Only in 2 cases, bleeding persisted after EMR and were managed successfully by the application of bipolar coagulation.

Table 4: Comparison between group A patients and group B patients regarding agreement between biopsy based and EMR based diagnoses.

\begin{tabular}{|c|c|c|c|c|c|c|c|}
\hline & \multicolumn{2}{|c|}{ Group A } & \multicolumn{2}{|c|}{ Group B } & \multicolumn{2}{|c|}{ Total } & $P$ value \\
\hline & no & $\%$ & no & $\%$ & no & $\%$ & \multirow{6}{*}{1.00} \\
\hline Agreement & 7 & 29.17 & 7 & 29.17 & 14 & 58.33 & \\
\hline \multirow[t]{4}{*}{ Disagreement } & 5 & 20.83 & 5 & 20.83 & 10 & 41.67 & \\
\hline & 4 & 16.67 & 5 & 20.83 & 9 & 37.50 & \\
\hline & 1 & 4.17 & 0 & 0.00 & 1 & 4.17 & \\
\hline & 12 & 50.00 & 12 & 50.00 & 24 & 100.00 & \\
\hline \multicolumn{3}{|c|}{$\begin{array}{l}\text { DISCUSSION } \\
\text { The importance of endoscopic surveillance of } \\
\text { 3arrett's esophagus (BE) for early detection of } \\
\text { lysplastic or neoplastic changes is well } \\
\text { stablished. }{ }^{(6,23)} \text { Histopathologic examination of the }\end{array}$} & \multicolumn{5}{|c|}{$\begin{array}{l}\text { resected mucosa enables not only an accurate } \\
\text { diagnosis but also grading of dysplasia and } \\
\text { neoplasia. } \\
\text { Upon endoscopic surveillance, } 4 \text { quadratic biopsies } \\
\text { are to be taken from BE segment. Moreover, visible }\end{array}$} \\
\hline
\end{tabular}


prominent lesions found related to BE segment are indicated for biopsy sampling or even endoscopic resection independently on the result of histological examination of biopsies. Further endoscopic interventions or surgical interference may be indicated based on the result of biopsy examination, such as RFA for HGD or IMC and esophagectomy for invasive $\mathrm{EAC}{ }^{(7)}$

The question was whether biopsies from $\mathrm{BE}$ segment or its related esophageal lesions are sufficient for accurate diagnosis and histologic grading. It is logical that the examination of large mucosal samples gained after EMR provides more information versus small biopsy. However, the difference in diagnostic accuracy was not sufficiently challenged in big trials. The aim of this prospective study was to clear whether the agreement in histopathologic diagnosis between forceps biopsies and EMR is sufficient when examining $\mathrm{BE}$ and its related superficial lesions.

In this study, done on 24 patients with BE undergoing surveillance endoscopy, an agreement between biopsy based and EMR based diagnoses was found only in 14 cases (58.33\%), and a disagreement between them was found in 10 cases (41.67\%). An EMR based upgrading diagnosis was made in 9 cases $(37.5 \%$ ), while an EMR based downgrading diagnosis was made by EMR in one case $(4.17 \%)$. The frequency of agreement and disagreement between biopsy and EMR were identical among patients with sampled mucosa from BE (group 1) or from related esophageal superficial lesions (group 2).The biggest disagreement (57.14\%) between biopsy and EMR diagnoses was found in patients with biopsy finding of LGD, the second big disagreement $(50 \%)$ was found in patients with biopsy finding of HGD.

Multiple studies showed results consistent with the findings of this study. Larghi et al., (2005) found in a series of $40 \mathrm{BE}$ patients undergoing EMR, that six of $25(24 \%)$ patients diagnosed initially with HGD were upgraded to IMC and six of $15(40 \%)$ patients with IMC were upgraded to invasive EAC. ${ }^{(24)}$ In the single-center study of Chennat et al., (2009) including $49 \mathrm{BE}$ patients, EMR resulted in a change of diagnosis in $22(44.8 \%)$ patients (upstaging for $14 \%$ and downstaging for $31 \%$ ) compared with pre-EMR biopsy results. ${ }^{(19)}$ In their study on the effect of EMR on histologic grading and staging for 75 BE patients with biopsy-proved HGD or EAC, Moss et al., (2010) reported that EMR resulted in a change of diagnosis for $48 \%$ of patients (downstaging for $28 \%$ and upstaging for $20 \%$ ). ${ }^{(25)}$ Similar results to the findings of the current study were concluded from a recent multi-center study of Wani et al., (2013), done on 138 known patients of $\mathrm{BE}$ (with or without endoscopically visible lesions) undergoing endoscopic eradication therapy; EMR resulted in a change of diagnosis for $31.1 \%$ patients (upgrade $10.1 \%$ and downgrade $21 \%$ ). ${ }^{(26)}$ The discrepancy between the two studies regarding the frequency of EMR based upgrading/downgrading could be explained by the different inclusion criteria; as only selected histologic grades of BE lesions were included in the study of Wani et al. $(2013),{ }^{(26)}$ while, all histologic grades of BE lesions were included in the current study.

Multiple retrospective studies had shown that examination of the EMR samples bring greater interobserver agreement (among pathologists) of BE and its related neoplasia compared to biopsied samples, and these studies have suggested that the diagnostic yield of EMR is higher compared to Biopsies. ${ }^{(27-29)}$

There was only one case of IAC in this study, that was diagnosed in agreement by both biopsy and EMR. This was possibly because of CT confirmation of mediastinal lymph node metastasis before biopsy. This patient was referred for surgery. Nine patients were referred for endoscopic intervention (RFA), with EMR based established diagnoses of HGD (5 cases) and IMC (4 cases). Five out of these nine cases $(55.56 \%)$ had previous biopsy based lower grading diagnoses (NDBE/LGD) that did not mandate any intervention. From above findings, more than half of the cases indicating endoscopic intervention, could miss the needed intervention if the diagnosis was based only on biopsy result.

Consistent with the above results, a group of pathologists from Japan and Germany have recently reported that, with regard to $\mathrm{BE}$ related early neoplasia (HGD/IMC), the indications for endoscopic intervention or major surgery cannot be decided on the basis of biopsy histology, and the choice between them should be made according to the invasion depth known after mucosal resection. ${ }^{(30)}$ They added, such lesions should not be managed by endoscopic ablation (e.g. RFA) alone, but by endoscopic resection (EMR/submucosal dissection) because components of invasive carcinoma are frequently present in the mucosa and submucosa, 
and knowledge obtained from resected mucosal samples is needed for additional therapy. ${ }^{(30)}$

The combination of EMR/RFA is the gold standard for the treatment of early neoplasms of the esophagus at the field of BE. This treatment leads to the eradication of neoplasia in $90 \%$ of patients and the percentage of recurrence is almost nil. ${ }^{(31)}$ Ablation therapy (RFA) is however, exceptionally indicated solely, in BE patients with HGD with long segments of flat-type mucosa (without visible lesion), where endoscopic resection is burdened with complications, especially the emergence of stenosis. ${ }^{(32)}$

It has been published alarming report from American authors; the detection of adenocarcinoma in three patients who underwent RFA for HGD in the field of BE, carcinoma was diagnosed a few months after the end of RFA treatment. ${ }^{(14)}$ It can be assumed that carcinoma could have been in, when RFA was performed, but could not be caught up by simple biopsy based histopathologic examination. Reason to believe why cancer was present at the time of RFA treatment is the presence of carcinoma in the surgical resection specimens from a significant percentage (sometimes around one third) of patients with an initial diagnosis of HGD, who had been in the past decade indicated for esophagectomy. ${ }^{(33)}$

The discrepancy between the EMR and biopsy may be due to several reasons. The first is undoubtedly good size and orientation of the sample after endoscopic resection, as well as the ability to evaluate mucosal landmarks, such as double muscularis mucosae. Another reason for this difference is that the sample of EMR includes (in most cases) a part of the submucosa, and hence are better evaluated. ${ }^{(26,28)}$

Finally, we concluded that standard biopsies are not sufficient for accurate diagnosis and classification of dysplasia and neoplasia in the esophagus in patients with $\mathrm{BE}$ and its related superficial esophageal lesions. EMR is crucial before proceeding to endoscopic ablation therapy or surgical interference in such patients.

\section{ACKNOWLEDGMENT}

Great thanks to all patients who have participated in this study, as well as to the histopathologists and nursing staff for their great efforts and help to carry out this work.

\section{REFERENCES}

1. Cossentino MJ, Wong RK. Barrett's esophagus and risk of esophageal adenocarcinoma. Semin Gastrointest Dis. 2003 Jul; 14(3):128-35.
2. Seewald S, Ang TL, Soehendra N. Endoscopic mucosal resection of Barrett's esophagus containing dysplasia or intramucosal cancer. Postgrad Med J. 2007 June; 83: 367-372.

3. Sharma P, McQuaid K, Dent J. Fennerty MB, Sampliner R, Spechler S, Cameron A, Corley D, Falk G, Goldblum J, Hunter J, Jankowski J, Lundell L, Reid B, Shaheen NJ, Sonnenberg A, Wang K, Weinstein W. A critical review of the diagnosis and management of Barrett's esophagus: the AGA Chicago workshop. Gastroenterology. 2004; 127:310 330.

4. Reid B J, Levine D S, Longton G., Blount PL, Rabinovitch PS. Predictors of progression to cancer in Barrett's esophagus: baseline histology and flow cytometry identify low and high risk patient subsets. Am J Gastroenterol. $2000 \mathrm{Jul}$; 95(7):1669-76.

5. Wang K , Sampliner R . Updated guidelines 2008 for the diagnosis, surveillance and therapy of Barrett's esophagus. Am J Gastroenterol. 2008; 103:788-797.

6. Spechler SJ, Sharma P, Souza RF, Inadomi JM, Shaheen NJ. American Gastroenterological Association medical position statement on the management of Barrett's esophagus. Gastroenterology. 2011 Mar; 140(3):1084-91.

7. Bennett C, Vakil N, Bergman J, Harrison R, Odze R, Vieth M, Sanders S, Gay L, Pech O, Longcroft-Wheaton G, Romero Y, Inadomi J, Tack J, Corley DA, Manner H, Green S, Al Dulaimi D, Ali H, Allum B, Anderson M, Curtis H, Falk G, Fennerty MB, Fullarton G, Krishnadath K, Meltzer SJ, Armstrong D, Ganz R, Cengia G, Going JJ, Goldblum J, Gordon C, Grabsch H, Haigh C, Hongo M, Johnston D, Forbes-Young R, Kay E, Kaye P, Lerut T, Lovat LB, Lundell L, Mairs P, Shimoda T, Spechler S, Sontag S, Malfertheiner P, Murray I, Nanji M, Poller D, Ragunath K, Regula J, Cestari R, Shepherd N, Singh R, Stein HJ, Talley NJ, Galmiche JP, Tham TC, Watson P, Yerian L, Rugge M, Rice TW, Hart J, Gittens S, Hewin D, Hochberger J, Kahrilas P, Preston S, Sampliner R, Sharma P, Stuart R, Wang K, Waxman I, Abley C, Loft D, Penman I, Shaheen NJ, Chak A, Davies G, Dunn L, Falck-Ytter Y, Decaestecker J, Bhandari P, Ell C, Griffin SM, Attwood $\mathrm{S}$, Barr H, Allen J, Ferguson MK, Moayyedi P, Jankowski JA. Consensus statements for management of Barrett's dysplasia and early stage esophageal adenocarcinoma, based on a Delphi process. Gastroenterology. 2012 Aug; 143(2):336-46.

8. Fitzgerald RC, di Pietro M, Ragunath K, Ang Y, Kang JY, Watson P, Trudgill N, Patel 
P, Kaye PV, Sanders S, O'Donovan M, BirdLieberman E, Bhandari P, Jankowski JA, Attwood S, Parsons SL, Loft D, Lagergren J, Moayyedi P, Lyratzopoulos G, de Caestecker J. British Society of Gastroenterology guidelines on the diagnosis and management of Barrett's esophagus. Gut. 2014 Jan; 63(1):742.

9. Kantsevoy SV, Adler DG, Conway JD, Diehl DL, Farraye FA, KwonR, Mamula P, Rodriguez S, Shah RJ, Wong Kee Song LM, Tierney WM. ASGE Technology Committee. Endoscopic mucosal resection and endoscopic submucosal dissection. Gastrointest Endosc. 2008; 68(1):8-11.

10. Inoue $\mathrm{H}$, Takeshita $\mathrm{K}$, Hori $\mathrm{H}$, Muraoka $\mathrm{Y}$, Yoneshima H, Endo M. Endoscopic mucosal resection with a cap-fitted panendoscope for esophagus, stomach, and colon mucosal lesions. Gastrointest Endosc.1993; 39:58-62.

11. Akiyama M, Ota M, Nakajima H, Yamagata K, Munakata A. Endoscopic mucosal resection of gastric neoplasms using a ligating device. Gastrointest Endosc.1997; 45:182-6.

12. Larghi A, Waxman I. State of the art on endoscopic mucosal resection and endoscopic submucosal dissection. Gastrointest Endosc Clin N Am. 2007; 17:441-69.

13. Alvarez Herrero L, Pouw RE, van Vilsteren FG, ten Kate FJ, Visser M, Seldenrijk CA, van Berge Henegouwen MI, Weusten BL, Bergman JJ. Safety and efficacy of multiband mucosectomy in 1060 resections in Barrett's esophagus. Endoscopy. 2011; 43:177-83.

14. Titi M, Overhiser A, Ulusarac O, Falk GW, Chak A, Wang K, Sharma P. Development of high-grade subsquamous dysplasia and adenocarcinoma after successful radiofrequency ablation of Barrett's esophagus. Gastroenterology. 2012; 143(3): 564-366.

15. Kim MP, Brown KN, Schwartz MR, Blackmon SH. Advanced esophageal cancer in patients who underwent radiofrequency ablation for Barrett's esophagus with high-grade dysplasia. Innovations (Phila). 2013 Jan-Feb; 8(1):17-22.

16. Endoscopic Classification Review Group. Update on the Paris classification of superficial neoplastic lesions in the digestive tract. Endoscopy. 2005; 37(6):570-578.

17. Han KS, Sohn DK, Choi DH, Hong CW, Chang HJ, Lim SB, Choi HS, Jeong SY, Park JG. Prolongation of the period between biopsy period between biopsy and EMR can influence the nonlifting sign in endoscopically resectable colorectal cancers. Gastrointest Endosc. 2008 Jan; 67(1):97-102.

18. Conio M, Repici A, Demarquay JF, Blanchi S, Dumas R, Filiberti R. EMR of large sessile colorectal polyps. Gastrointest Endosc. 2004 Aug; 60(2):234-41.

19. Chennat J, Konda VJ, Ross AS, de Tejada AH, Noffsinger A, Hart J. Complete Barrett's eradication endoscopic mucosal resection: an effective treatment modality for high-grade dysplasia and intramucosal carcinoma-an American single-center experience. Am J Gastroenterol. Nov 2009; 104(11):2684-92.

20. Montgomery E, Bronner MP, Goldblum JR. Reproducibility of the diagnosis of dysplasia in Barrett's esophagus: a reaffirmation. Hum Pathol. 2001; 32:368-78.Kim MP, Brown KN, Schwartz MR, Blackmon SH. Advanced esophageal cancer in patients who underwent radiofrequency ablation for Barrett's esophagus with high-grade dysplasia. Innovations (Phila). 2013 Jan-Feb; 8(1):17-22.

21. Schlemper RJ, Riddell RH, Kato Y, Borchard F, Cooper HS, Dawsey SM, Dixon MF, FenoglioPreiser CM, Fléjou JF, Geboes K, Hattori T, Hirota T, Itabashi M, Iwafuchi M, Iwashita A, Kim YI, Kirchner T, Klimpfinger M, Koike M, Lauwers GY, Lewin KJ, Oberhuber G, Offner F, Price AB, Rubio CA, Shimizu M, Shimoda T, Sipponen P, Solcia E, Stolte M, Watanabe H, Yamabe $\mathrm{H}$. The Vienna classification of gastrointestinal epithelial neoplasia. Gut. 2000; 47: 251-255.

22. Landis J, Koch GG. The measurement of observer agreement for categorical data. Biometrics. 1977; 33:159-174.

23. Lim YC, Fitzgerald RC. Diagnosis and treatment of Barrett's esophagus. Br Med Bull. 2013; 107:117-32.

24. Larghi A, Lightdale CJ, Memeo L, Bhagat G, Okpara N, Rotterdam H. EUS followed by EMR for staging of high-grade dysplasia and early cancer in Barrett's esophagus. Gastrointest Endosc. 2005; 62:16-23.

25. Moss A, Bourke MJ, Hourigan LF, Gupta S, Williams SJ, Tran K, Swan MP, Hopper AD, Kwan V, Bailey AA. Endoscopic resection for Barrett's high-grade dysplasia and early esophageal adenocarcinoma: an essential staging procedure with long-term therapeutic benefit. Am J Gastroenterol. 2010; 105:1276-1283.

26. Wani S, Abrams J, Edmundowicz SA, Gaddam S, Hovis CE, Green D, Gupta N, Higbee A, Bansal A, Rastogi A, Early D, Lightdale CJ, Sharma P. Endoscopic mucosal resection results in change of histologic diagnosis in Barrett's esophagus patients with visible and flat neoplasia: a multicenter cohort study. Dig Dis Sci. 2013 Jun; 58(6):1703-9.

27. Hull MJ, Mino-Kenudson M, Nishioka NS, Ban S, Sepehr A, Puricelli W, Nakatsuka L, Ota S, 
Shimizu M, Brugge WR, Lauwers GY. Endoscopic mucosal resection: an improved diagnostic procedure for early gastroesophageal epithelial neoplasms. Am J Surg Pathol. 2006; 30(1):114-118.

28. Wani S, Mathur SC, Curvers WL, Singh V, Alvarez Herrero L, Hall SB, Ulusarac O, Cherian R, McGregor DH, Bansal A, Rastogi A, Ahmed B, Singh M, Gaddam S, Ten Kate FJ, Bergman J, Sharma P. Greater interobserver agreement by endoscopic mucosal resection than biopsy samples in Barrett's dysplasia. Clin Gastroenterol Hepatol. 2010; 8(9):783-788.

29. Mino-Kenudson M, Hull MJ, Brown I, Muzikansky A, Srivastava A, Glickman J, Park DY, Zuckerberg L, Misdraji J, Odze RD, Lauwers GY. EMR for Barrett's esophagusrelated superficial neoplasms offers better diagnostic reproducibility than mucosal biopsy. Gastrointest Endosc. 2007 Oct; 66(4):660-6.

30. Takubo K, Vieth M, Aida J, Matsutani T, Hagiwara N, Iwakiri K, Kumagai Y, Hongo
M, Hoshihara Y, Arai T. Histopathological diagnosis of adenocarcinoma in Barrett's esophagus. Dig Endosc. 2013 Aug;25.

31. Phoa KN, Pouw RE, van Vilsteren FG, Sondermeijer CM, Ten Kate FJ, Visser M, Meijer SL, van Berge Henegouwen MI, Weusten BL, Schoon EJ, Mallant-Hent RC, Bergman JJ. Remission of Barrett's esophagus with early neoplasia 5 years after radiofreuency ablation with endoscopic resection: A Netherlands Cohort Study Gastroenterlogy. 2013; 145(1):96-104.

32. van Vilsteren FG, Bergman JJ. Endoscopic therapy using radiofrequency ablation for esophageal dysplasia and carcinoma in Barrett's esophagus. Gastrointest Endosc Clin. 2010; 20(1):55-74.

33. Reed MF, Tolis G Jr, Edil BH, Allan JS, Donahue DM, Gaissert HA, Moncure AC, Wain JC, Wright CD, Mathisen DJ. Surgical treatment of esophageal high-grade dysplasia. Ann Thorac Surg. $\quad 2005 \quad$ Apr; 79(4):1110-5. 